\title{
TENDON INJURIES AROUND THE ANKLE
}

\author{
J. C. Griffiths, Glasgow, Scotland
}

From the Western Infirmary, Glasgow

The late consequences of accidental tendon division in the foot and ankle are seldom appreciated, for these injuries are rare, apart from rupture of tendo calcaneus. Nevertheless such injuries do occur, both open and closed, and it is the purpose of this communication to draw attention to the unfortunate results of ineffective treatment.

Lipscomb and Kelly (1955) described thirteen patients in whom tendons at the front of the ankle had been accidentally divided. Two of these were young children and repair failed in spite of adequate primary surgery. Mensor and Ordway (1953) described two cases of closed rupture of the tibialis anterior tendon and reviewed a further ten from the literature. This injury occurs in older persons and appears to be the analogue of closed rupture of tendo calcaneus. Provided the foot is otherwise normal, examination of its posture and function after accidental tendon division presents a unique study in functional anatomy. The cases to be described were the result of injury to a normal foot and in most of them only one tendon was divided.

\section{MATERIAL}

Twenty patients who had sustained injury to foot tendons other than tendo calcaneus were traced in the records. Only one of these was a closed injury, in a tendon which was shown at operation to have been eroded by rheumatoid tissue. Nine patients were traced and personally reviewed; in the remainder adequate records were available except in one patient who was lost to follow-up at an early stage. The patients in the series are listed in Table I. Most of the tendons in the foot are represented. Seven of the injuries were in patients aged ten years or under. An immediate repair had been carried out in eleven patients; in five patients no attempt had been made to suture the divided tendon, and in four patients the first attempt at repair was not made until several weeks or months after the original injury. Repair of the tendons was made with various forms of unabsorbable suture material. In most patients a plaster was added for splintage except for repair of the tendon of extensor hallucis longus.

\section{RESULTS}

When immediate tendon repair was made there was full recovery of function within three months. Only three of these patients were traced for a personal review; none had any disability.

When repair was not carried out, spontaneous recovery occurred twice, once after division of the extensor hallucis longus tendon, and once after division of extensor digitorum communis. In a third case, that of a closed rupture of tibialis posterior in an adult, the foot was of normal shape and function when examined two years later, but the tendon was no longer acting. The two remaining patients sustained their injuries during the growing period and now have severe deformities.

In the third group of patients repair was delayed for periods ranging from one month to three years. Only one of these patients was adult and had a divided tibialis anterior tendon repaired at four months. This patient was the only one in whom a satisfactory result was obtained.

Five patients developed deformity and disability as a result of injury to a single tendon in an otherwise normal foot. In one patient the picture was complicated by a skeletal injury sustained at the same time. The peroneal tendons were involved three times and the tibialis posterior and tibialis anterior tendons once each. 
TABLE I

The Tendons Involved and the Treatment Undertaken

\begin{tabular}{|c|c|c|c|c|}
\hline $\begin{array}{c}\text { Case } \\
\text { number }\end{array}$ & $\begin{array}{l}\text { Age at } \\
\text { injury } \\
\text { (years) }\end{array}$ & Tendons involved & Treatment & Result \\
\hline 1 & 4 & Extensor hallucis longus & Immediate repair & Satisfactory \\
\hline 2 & 5 & Peroneal & No repair & Unsatisfactory \\
\hline 3 & 8 & Tibialis posterior & Repair after 3 years & Unsatisfactory \\
\hline 4 & 9 & Peroneal & Repair after 14 months & Unsatisfactory \\
\hline 5 & 10 & Peroneus longus & Immediate repair & $\begin{array}{l}\text { Short follow-up only. } \\
\text { Appeared satisfactory }\end{array}$ \\
\hline 6 & 10 & $\begin{array}{l}\text { Tibialis posterior } \\
\text { Tibialis anterior }\end{array}$ & $\begin{array}{l}\text { Immediate repair of tibialis } \\
\text { posterior. Repair of tibialis } \\
\text { anterior after } 2 \text { years }\end{array}$ & Unsatisfactory \\
\hline 7 & 10 & Peroneal & No repair & Unsatisfactory \\
\hline 8 & 14 & Extensor digitorum communis & Immediate repair & Satisfactory \\
\hline 9 & 19 & $\begin{array}{l}\text { Extensor hallucis longus } \\
\text { Extensor digitorum communis }\end{array}$ & Immediate repair & Satisfactory \\
\hline 10 & 21 & Extensor hallucis longus & No repair & Satisfactory \\
\hline 11 & 22 & Extensor hallucis longus & Immediate repair & Satisfactory \\
\hline 12 & 23 & Extensor hallucis longus & Immediate repair & Satisfactory \\
\hline 13 & 24 & Extensor digitorum communis & Immediate repair & Satisfactory \\
\hline 14 & 25 & Extensor hallucis longus & Immediate repair & Satisfactory \\
\hline 15 & 25 & Extensor digitorum communis & No repair & Satisfactory \\
\hline 16 & 30 & Peroneal & Immediate repair & Satisfactory \\
\hline 17 & 35 & $\begin{array}{l}\text { Tibialis posterior } \\
\text { (spontaneous rupture) }\end{array}$ & No repair & Satisfactory \\
\hline 18 & 40 & Tibialis anterior & Repair after 4 months & Satisfactory \\
\hline 19 & 42 & $\begin{array}{l}\text { Tibialis posterior } \\
\text { Flexor digitorum longus }\end{array}$ & Immediate repair & Satisfactory \\
\hline 20 & 54 & Tibialis anterior & Immediate repair & Satisfactory \\
\hline
\end{tabular}

\section{CASE REPORTS}

Case 6-A boy of ten sustained a laceration on the medial side of his foot and division of the tibialis posterior tendon. Repair was carried out a month later. It later became apparent that there was a pronation deformity and impaired dorsiflexion of the foot. Exploration two years after the injury revealed that the tibialis anterior had also been divided at the initial injury. The long fibrous union was excised and an attempt made to restore continuity of the tendon. This failed and a year later the foot was re-explored, tenolysis carried out and the extensor hallucis longus attached to the medial cuneiform bone. The foot remained everted and the patient could not attain 90 degrees dorsiflexion. A caliper was worn until he was thirteen. When he was reviewed again at seventeen he did not complain of any disability, but still had no function in tibialis anterior and normal function in all the other foot tendons. The foot was pronated and swung into more pronation on attempts at dorsiflexion due to the unopposed action of the peroneus longus. The tibialis posterior muscle which had been repaired shortly after the original injury was functioning normally. There was obvious wasting of the tibialis anterior muscle, but in spite of this, normal action potentials could still be obtained from it. The appearance of the foot in full dorsiflexion is shown in Figure 1.

VOL. 47 B, NO. 4, NOVEMBER 1965 


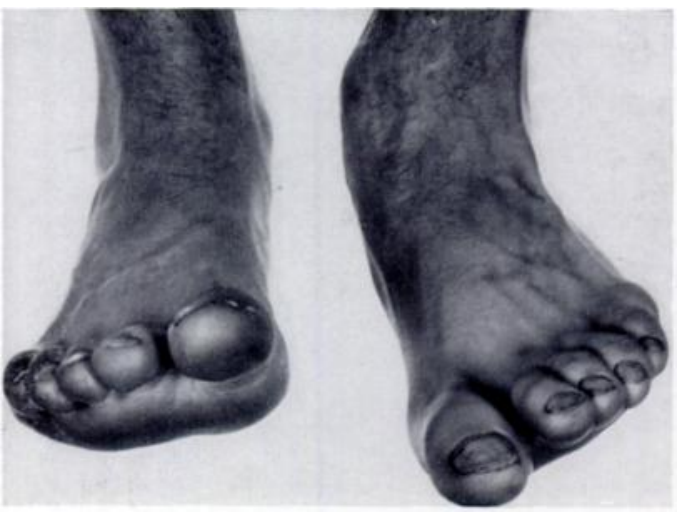

FiG. 1

Case 6-Showing pronation of the foot in dorsiflexion.

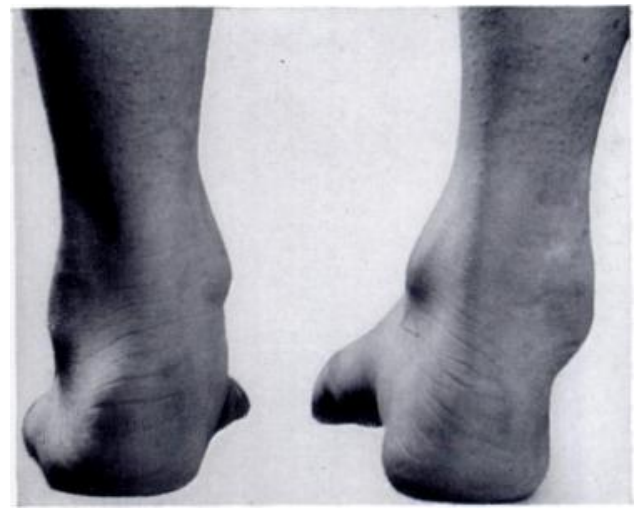

FIG. 2

Case 4-Showing the varus heel and failure of the first metatarsal to reach the ground when standing.

Case 4-A girl of nine was seen fourteen months after a minor laceration below the lateral malleolus which had been ignored at the time. She had a foot deformity which her parents did not relate to the earlier injury. Repair of the divided peroneal tendons was attempted; this proved difficult and the tendon ends were brought together under tension. This operation was a failure. On examination two years later the foot was supinated. When the child walked or stood in bare feet the first metatarsal head did not reach the ground. The foot became supinated on dorsiflexion due to the unopposed pull of the tibialis anterior muscle. The lateral malleolus was prominent and the heel was in varus (Fig. 2). A lateral sole wedge failed to control the supination. In spite of the wedge there was no appreciable wear on the medial border of the sole. Although there had been no function in the affected muscles for three years, normal action potentials could still be obtained on electromyography. This patient has recently been treated by transposition of the tibialis anterior to the fourth metatarsal.

Case 2-A boy of five sustained a severe degloving injury to the lateral side of the leg. The tendons and a large part of the muscle bellies of the peronei were avulsed. At the time there was no obvious skeletal injury apart from scraping of the lower end of fibula. Skin cover was obtained by the use of a pedicle flap. There was no possibility of reconstituting the peronei and a year later a caliper became necessary to control inversion. When the patient was seen some years later there was severe valgus of the foot (Fig. 3) and it was only on asking him to dorsiflex strongly that the peroneal deficit was unmasked, as the forefoot then became supinated (Fig. 4). A radiograph showed that the cause of the valgus deformity was epiphysial arrest of the lower end of the fibula (Fig. 5). This incidental bony deformity has now been corrected by tibial osteotomy.

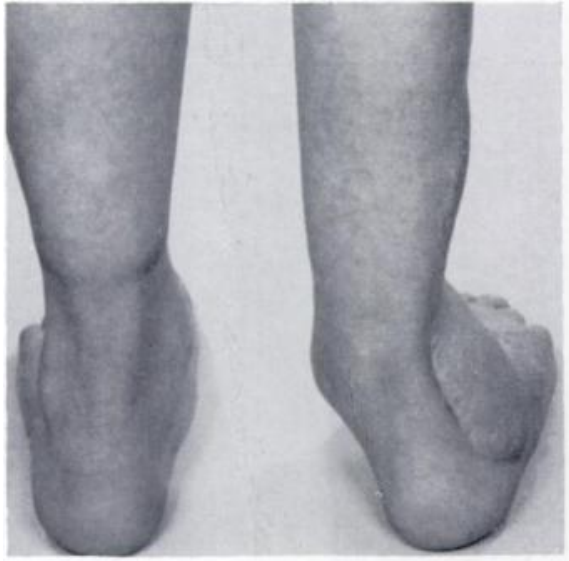

Fici 3

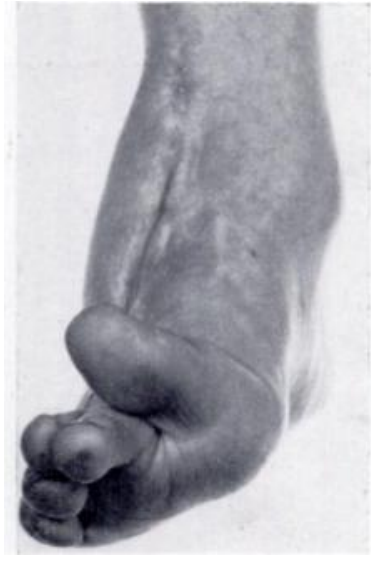

Fig. 4

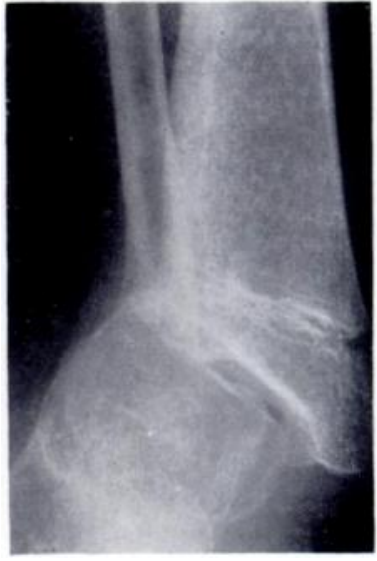

Fig. 5

Case 2. Figure 3-Showing the valgus foot. Figure 4-Showing supination of the forefoot on dorsiflexion. Figure 5-Radiograph showing premature epiphysial fusion at the lower end of the fibula causing valgus. 
Case 7-A man of forty sought treatment for an unstable and deformed foot. The deformity had gradually developed after a minor laceration of the ankle thirty years before. The patient had the clinical features of the patient in Case 4 , but to a more advanced degree. There was marked inversion of the heel as well as forefoot supination and the deformity was fixed. A radiograph of the ankle showed fixed varus of the talus unchanged by stress films. Whereas the patient in Case 4 had no symptoms at the age of twelve, this patient was now complaining of ankle instability, especially when walking on uneven ground. The deformity was undoubtedly the result of neglected division of the peronei at the age of ten.

Case 3-A child of eight presented with a foot deformity attributed to a laceration on the medial side of the ankle sustained three years before and ignored at the time. The foot was in valgus with complete loss of the longitudinal arch. A bony prominence below and slightly anterior to the medial malleolus was shown radiologically to be the partly uncovered head of the talus. There was no detectable function in the tibialis posterior muscle and there was some loss of bulk in the calf. At exploration the divided ends of the tendon were found and drawn together with difficulty. The operation was a failure. When reviewed two years later the foot still showed the same deformity as described by Fried and Hendel (1957).

\section{DISCUSSION}

Complete recovery of function can be expected after a successful and early repair of these tendon injuries. Formal repair of extensor hallucis longus seems unnecessary: its natural tendency to spontaneous repair after tenotomy is well known. Experience with adults in this series is limited, but repair of a tibialis anterior tendon after a delay of four months was successful, and a patient with a closed rupture of the tibialis posterior tendon, which was not repaired, had not developed any obvious deformity or disability two years later. In children the results are much less satisfactory and early diagnosis and repair of the divided tendon is imperative. The plastic nature of the foot at this age allows deformity to develop so rapidly that failure of a late tendon repair seems inevitable. It seems unfortunate that muscles which are still electrically active have not been utilised at a late stage. The use of a tendon graft to relieve tension in late repair has apparently not been tried except in cases of ruptured tibialis anterior (Moberg 1947).

It should be stressed that sacrifice of a single tendon in the foot of a normal child is disastrous. This does not, however, seem true in the abnormal foot. It is, for instance, possible to divide or lengthen the tibialis posterior tendon in club foot and to reroute various tendons in paralytic feet without producing the deformity which might be expected.

\section{SUMMARY}

1. An account is given of twenty patients who had sustained accidental division of one or more foot tendons (other than tendo calcaneus).

2. Severe deformities occur when these injuries are neglected in children.

I should like to thank $\mathrm{Mr} \mathrm{N}$. J. Blockey, who originally suggested this study, and $\mathrm{Mr} \mathrm{T}$. W. Howat for permission to examine cases under their care. My thanks also are due to Mr C. Sorbie for electromyographic studies and to both Professor R. Barnes and Mr N. J. Blockey for encouragement and for criticism of the script. The illustrations were prepared by $\mathrm{Mr} \mathrm{J}$. Devlin of the Royal Hospital for Sick Children, Glasgow, and Mr G. Donald of the Western Infirmary, Glasgow.

\section{REFERENCES}

Fried, A., and Hendel, C. (1957): Paralytic Valgus Deformity of the Ankle. Journal of Bone and Joint Surgery, 39-A, 921.

Lipscomb, P. R., and Kelly, P. J. (1955): Injuries of the Extensor Tendons in the Distal Part of the Leg and in the Ankle. Journal of Bone and Joint Surgery, 37-A, 1206.

Mensor, M. C., and Ordway, G. L. (1953): Traumatic Subcutaneous Rupture of the Tibialis Anterior Tendon. Journal of Bone and Joint Surgery, 35-A, 675.

Moberg, E. (1947): Subcutaneous Rupture of the Tendon of the Tibialis Anterior Muscle. Acta Chirurgica Scandinavica, 95, 455.

VOL. 47 B, NO. 4, NOVEMBER 1965 